\title{
Long-Term Donor Outcomes after Pure Laparoscopic versus Open Living Donor Nephrectomy: Focus on Pregnancy Rates, Hypertension and Quality of Life
}

\author{
Frank Friedersdorff ${ }^{a}$ Lisa Kothmann ${ }^{a}$ Philipp Manus ${ }^{a}$ Jan Roigas ${ }^{c}$ \\ Carsten Kempkensteffen ${ }^{a} \quad$ Ahmed Magheli $^{\mathrm{a}}$ Jonas Busch ${ }^{\mathrm{a}}$ Lutz Liefeldt $^{\mathrm{b}}$ \\ Markus Giessing ${ }^{d}$ Serdar Deger ${ }^{\mathrm{e}}$ Martin Schostak ${ }^{f}$ Kurt Miller $^{\mathrm{a}}$ \\ Tom Florian Fuller ${ }^{a}$ \\ ${ }^{a}$ Department of Urology and ${ }^{b}$ Department of Nephrology, Charité University Hospital, ' Department of Urology, \\ Hospital Friedrichshain, Berlin, ${ }^{d}$ Department of Urology, Heinrich-Heine-University Düsseldorf, Düsseldorf, \\ e Department of Urology, Paracelsus Hospital, Ruit, and f Department of Urology, University Hospital, \\ Magdeburg, Germany
}

\section{Key Words}

Fatigue syndrome · Female donor · Hypertension .

Laparoscopic donor nephrectomy - Long term follow-up ·

Open donor nephrectomy · Pregnancy

\begin{abstract}
Introduction: The aim of the present study was to compare long-term donor outcomes after open and laparoscopic living donor nephrectomy. The focus was on pregnancy rates, hypertension and quality of life parameters. Materials and Methods: Data were retrospectively collected using our institution's electronic database and a structured questionnaire. The study included 30 donors after open donor nephrectomy (ODN) and 131 donors after laparoscopic donor nephrectomy (LDN). Results: Demographic data did not differ between groups. When asked for their preference, significantly more donors in the LDN group would choose the same surgical approach again. The overall frequency of postoperative complications was significantly lower in the LDN
\end{abstract}

group. The incidence of grade III complications was $2 \%$ after LDN and $10 \%$ after ODN ( $p=0.79$ ). Only 2 out of 15 female donors aged between 18 and 45 years delivered a healthy child after DN. On interview, only 4 out of 15 female donors declared the desire to have children after DN. Conclusions: From the donor perspective, long-term outcomes after LDN are more favorable than after ODN. To ensure favorable functional outcomes, strict preoperative donor selection and diligent long-term donor follow-up are required.

(c) 2016 S. Karger AG, Basel

\section{Introduction}

Laparoscopic procurement of living donor kidneys is considered the gold standard for living donor renal transplantation in numerous renal transplant centers worldwide. The goal of laparoscopic donor nephrectomy (LDN) was improved cosmesis, shorter hospitalization and quicker return to work.

\section{KARGER}

E-Mail karger@karger.com

www.karger.com/uin
(C) 2016 S. Karger AG, Basel

0042-1138/16/0974-0450\$39.50/0 
The number of live kidney transplants has further risen in the past few years, whereby LDN is the gold standard in large transplant centers (open donor nephrectomy, ODN) [1]. We started LDN in 1999 and to date have carried out more than 500 pure laparoscopic non-handassisted procedures. We perform approximately 100 renal transplants per year, roughly $30-50 \%$ of which are living donor renal transplants.

In considering the possible long-term side effects for donors who undergo a nephrectomy, the most prominent ones are arterial hypertension, chronic renal failure and chronic fatigue syndrome (CFS). CFS is a condition exhibiting symptoms of exhaustion, which are associated and also observed with chronic cardiovascular disease and tumor morbidity. Part of the pathology is suspected to be an anemic state, which may occur due to reduced production of erythropoietin by the kidney. A study published in 2007 showed that the prevalence of CFS was greater after ODN than after LDN [2].

With respect to live kidney donations, women, on average, donate more than $50 \%$ of kidneys [3]. A proportion of these are still in the childbearing age. A physiologic pregnancy is characterized by the increase in renal blood flow and glomerular filtration rate (GFR) [4], which requires particular surveillance of creatinine for pregnant women who in the past have undergone kidney donation. Also, there is a potential increase in the possibility of preeclampsia [5]. The risk of preeclampsia is increased compared to pregnancies prior to live kidney donation, however not when compared to the average population [6]. Aside from this risk, the willingness for a pregnancy after kidney donation requires further investigation.

Ibrahim et al. [1] investigated GFR, albuminuria, hypertension, overall health status and quality of life for 255 donors from 2003 to 2007 and showed that survival and risk for end-stage renal disease for live kidney donors was comparable to the average population. Nonetheless, a mortality risk of $0.03 \%$ and a $22 \%$ risk for minor and $3-6 \%$ risk for major perioperative complications remain [7].

The purpose of this retrospective study was to investigate to what extent LDN is superior to ODN and compare the 2 surgical techniques from the donor perspective. Furthermore, the goal was to determine the health consequences that donors who undergo live kidney donation may experience with particular emphasis on development of CFS as well as compliance with pregnancy in women after kidney donation.

Laparoscopic vs. Open

Donornephrectomy

\section{Materials and Methods}

\section{Patients}

The Ethics Committee at Charité University Hospital Berlin approved this study. All patients provided written informed consent for this research study.

The study period included all live kidney donations from January 1, 2000, until December 31, 2010, at the Benjamin Franklin Campus $(\mathrm{n}=30)$ and from January 1, 2004, until December 31, 2009, at the Mitte Campus ( $\mathrm{n}=131$ ) of the Charité Hospital Berlin. LDNs were performed at the Mitte Campus while ODNs were carried out at the Benjamin Franklin Campus. Both transplant centers had different volumes of waiting list. For that reason, we had a difference in the number of patients included in each group of the study.

All donors underwent an extensive medical workup to rule out malignancies and chronic diseases. Renal vascular imaging was performed with multi-slice CT angiography and with MR angiography. Routine assessment of donor split renal function was carried out using 99mTC-MAG3 renography. In cases of a relevant difference between the left and the right donor kidney (i.e. $>5 \%$ difference in GFR), we procured the kidney with inferior function, regardless of the renal vascular anatomy.

\section{Outcome Parameters}

Several parameters were examined like creatinine level, blood pressure (BP), body mass index (BMI), proteinuria and medication. To estimate the economic impact and expenses of the procedures, the period of hospitalization and duration of sick leave were included. Pregnancies and abortions after the LDN serve to guide attention specifically to the donor compliance of women and how LDN affects their willingness to have a pregnancy after the procedure.

Furthermore, the occurrence or remainder of damages due to the surgery such as bleeding, blood transfusion, revision, organ loss, chylaszitis, wound healing dysfunctions, incisional hernia, wound relaxation, elevated transaminases, hematoma, chronic wound pain, paresthesia and CFS were evaluated.

Another important aspect in the comparison between the open and LDN is the patient's willingness to repeat the same procedure again, given the choice of both procedures. To evaluate this, patients were asked if they, based on their recent experience, would choose the same surgical technique in the hypothetical scenario that the surgery was repeated.

Quality of life also plays an important role in the complete evaluation of a patient's health status. The assessment tool used was developed in our hospital measuring tool of quality-of-life research and allows analysis of the health-related quality of life in a manner that is independent of current health status and age.

\section{Surgical Technique}

Laparoscopic Donor Nephrectomy

LDN was performed as a pure laparoscopic, non-hand-assisted procedure using a 4-port transperitoneal access. A pneumoperitoneum of $15 \mathrm{~mm} \mathrm{Hg}$ was routinely used. Arteries were secured with $12 \mathrm{~mm}$ Hemolock and titanium clips. For right-side LDN, the renal vein was secured with an Endo-TA multi-fire stapler, while the left renal vein was typically secured and transected with a vascular Endo-GIA stapler. Kidneys were extracted via a flank incision of approximately $6 \mathrm{~cm}$ in length before being flushed with ice-cold HTK solution. 
Table 1. Demographic data

\begin{tabular}{lccc}
\hline & ODN $(\mathrm{n}=30)$ & LDN $(\mathrm{n}=131)$ & $\mathrm{p}$ value \\
\hline Donor age & $51.5 \pm 10.6$ & $47.6 \pm 11.5$ & 0.09 \\
Creatinine preoperative, $\mathrm{mg} / \mathrm{dl}$ & $0.81 \pm 0.15$ & $0.82 \pm 0.15$ & 0.67 \\
BP preoperative, $\mathrm{mm} \mathrm{Hg}$ & $103.03 \pm 13.57$ & $103.47 \pm 10.62$ & 0.87 \\
Donor with BP medication before DN, \% & $17.9(5 / 28)$ & $14.2(14 / 98)$ & 0.64 \\
BMI preoperative, $\mathrm{kg} / \mathrm{m}^{2}$ & $25.8 \pm 3.2$ & $25.3 \pm 3.8$ & 0.45 \\
Female donor, \% & 67 & 77 & 0.37 \\
Follow-up, months & $94.3 \pm 39.3$ & $49 \pm 21$ & $0.001^{*}$ \\
\hline
\end{tabular}

All parameters were measured in average.

$* \mathrm{p}<0.05$ was statistically significant.

Table 2. Donor follow-up

\begin{tabular}{lccl}
\hline & ODN $(\mathrm{n}=30)$ & LDN $(\mathrm{n}=131)$ & p value \\
\hline Warm ischemia time, s & $65.18 \pm 36.22$ & $162.15 \pm 32.89$ & $0.001^{*}$ \\
Operation time, min & $171.53 \pm 30.66$ & $147 \pm 26.82$ & $0.01^{*}$ \\
Creatinine at discharge, $\mathrm{mg} / \mathrm{dl}$ & $1.28 \pm 0.3$ & $1.25 \pm 0.26$ & 0.5 \\
Hospital stay, days & $9.2 \pm 2.9$ & $6.2 \pm 2.4$ & $0.001^{*}$ \\
Sick leave, weeks & $7.7 \pm 5.4$ & $6.5 \pm 10.2$ & 0.59 \\
Hypothetical repetition DN, \% & 96 & 97 & 0.6 \\
Wish for same surgical technique, \% & 67 & 99 & $0.001^{*}$ \\
\hline
\end{tabular}

The parameters were measured as average.

$* \mathrm{p}<0.05$ was statistically significant.

Open Donor Nephrectomy

The ODN was performed through a retroperitoneal access via dorsolumbar flap incision. For this, the patient was placed either in a full or in half flank position [8]. The incision typically occurs intercostal between the 11th and 12th rib and should not exceed $12 \mathrm{~cm}$ in length. It may be lengthened medially if needed, as may be the case with obese patients. The left renal artery is ligated immediately after it branches off the aorta. The remaining renal arterial trunk is securely ligated or sown over. In case of a sufficiently long enough left or especially right renal vein, the vena cava and the respective renal vein are partially occluded using the Satinsky clamp. After transection of the renal vein, the vena cava is successively sown with non-resorbable sutures. The warm ischemia time normally remains under $90 \mathrm{~s}$ for the ODN. The musculature and fascia are stitched in a multi-layered fashion while the skin incision is stitched intracutaneously.

\section{Statistical Analysis}

SPSS 19.0 for Windows (SPSS Inc., Chicago, Ill., USA) was used for statistical analysis. For comparison of means \pm SD of continuous variables between the 2 study groups, the Student's t test was employed. Frequency data were compared between groups by the chi-square and Fisher's exact test. Two-sided $p$ values were reported. A p value of $<0.05$ was considered statistically significant.

\section{Results}

\section{Demographic Data of Live Kidney Donors}

Table 1 summarizes the demographic data of all the donors. No significant differences were observed with respect to age, preoperative creatinine levels, pre-operative BP medication, the proportion of female donors and BMI. The follow-up time of the ODN group was significantly longer with $94.3 \pm 39.3$ months as compared to the $49 \pm 21$ months of the LDN group $(p=0.001)$.

\section{Peri- and Postoperative Donor Data}

Table 2 summarizes all the postoperative donor data. The percentage of properly answered surveys was $80 \%$ in the ODN group and $76 \%$ in the LDN group. Total surgery duration was an average of $171.53 \pm 30.66 \mathrm{~min}$ in the ODN group, which was significantly longer than in the LDN group where the average was $147 \pm 26.82 \mathrm{~min}(\mathrm{p}=$ 0.01 ). Patients were discharged from the hospital on average after $6.2 \pm 2.4$ days and after $9.2 \pm 2.9$ days following LDN and ODN, respectively. This difference was 
Table 3. Long-term effects of DN

\begin{tabular}{|c|c|c|c|}
\hline & $\mathrm{ODN}(\mathrm{n}=30)$ & $\mathrm{LDN}(\mathrm{n}=131)$ & $\mathrm{p}$ value \\
\hline Creatinine (1 year), mg/dl & $1.27 \pm 0.2$ & $1.17 \pm 0.21$ & 0.07 \\
\hline Creatinine (4 years), mg/dl & $1.11 \pm 0.14$ & $1.12 \pm 0.27$ & 0.89 \\
\hline Proteinuria, \% & 23 & 2 & $0.001^{*}$ \\
\hline $\mathrm{BP}, \mathrm{mm} \mathrm{Hg}$ & $102.57 \pm 8.68$ & $104.29 \pm 10.93$ & 0.40 \\
\hline Hypertension $(\geq 140 / 80), \%$ & 8 & 14 & 0.52 \\
\hline Increase $\mathrm{BP}$ medication after $\mathrm{DN}, \%$ & 21.4 & 25.5 & 0.29 \\
\hline Fatigue syndrome, $\%$ & 17 & 8 & 0.15 \\
\hline
\end{tabular}

highly significant $(\mathrm{p}<0.001)$. Another significant difference was observed for answers to the question about which surgical technique patients would the patient choose in case of a repeated nephrectomy, given the $2 \mathrm{op}-$ tions. Ninety-nine percent of donors in the LDN group responded that they would choose the laparoscopic approach again, whereas only $76 \%$ of patients in the ODN group replied that they would undergo the open nephrectomy again $(\mathrm{p}=0.001)$.

At the time of the questionnaire, donors in the ODN group were aware of the fact that the quality of the LDN procedure was on par with the ODN procedure as well as the method of choice in many large kidney transplant centers.

No significant differences between the groups was found for creatinine levels at the time of hospital release, duration of sick leave or the hypothetical repetition of live kidney donation.

\section{Clavien-Dindo Classification}

Grades IV and V complications did not occur in our study group. Altogether, 47 Clavien classifiable complications (17 after ODN and 29 after LDN) were recorded among the study group.

The following percentual distribution was observed with Clavien grades I-III: grade I: $33 \%$ ODN vs. $12 \%$ LDN $(\mathrm{p}=0.01)$, grade II: $13 \%$ ODN vs. $8 \% \mathrm{LDN}(\mathrm{p}=0.30)$, grade III: $10 \%$ ODN vs. $2 \%$ LDN ( $\mathrm{p}=0.79$ ).

Particularly noticeable was the high proportion of flank relaxation, chronic wound pain, wound healing disturbances as well as surgical correction of incisional hernias following ODN. Complications associated with the extraction wound on the flanks of patients occurred only sporadically after LDN. Blood transfusion rate was slightly increased following LDN in comparison with following ODN but without significant differences (5 vs. $3 \%$ ).

Laparoscopic vs. Open

Donornephrectomy
An operative revision was required for 3 donors from the ODN ( $\mathrm{n}=2$ : incisional hernia, $\mathrm{n}=1$ : bleeding) and 2 donors from the $\operatorname{LDN}(\mathrm{n}=2$ : bleeding) groups. In cases of bleeding, small non-life-threatening intra-abdominal bleeds, which caused a decrease in the red blood count, were stopped. One female donor of the LDN group who required revision was diagnosed with a systemic heparin overdose, which was successfully antagonized with protamine. All LDNs were concluded as such, meaning no need for open conversion.

\section{Long-Term Effects of Donor Nephrectomy}

Table 3 summarizes follow-up care parameters, which are indicators for long-term consequences of live kidney donation. Patients were asked to indicate the progression of their creatinine levels, as determined via yearly checkups and possible proteinuria. The survey was sent to donors in 2011, thus on average 4 years and at least 1 year after live kidney donation. Serum creatinine and proteinuria were both determined during yearly routine checkups a year as well as 4 years after donation.

One year following hospital release, the average donor serum creatinine parameter in the ODN group was $1.27 \pm$ $0.2 \mathrm{mg} / \mathrm{dl}$ and $1.17 \pm 0.2 \mathrm{mg} / \mathrm{dl}$ in the LDN group ( $\mathrm{p}=$ $0.07)$. The 4 year serum creatinine parameter averaged $1.11 \pm 0.14 \mathrm{mg} / \mathrm{dl}$ and $1.12 \pm 0.27 \mathrm{mg} / \mathrm{dl}$ in in the ODN and LDN group, respectively $(\mathrm{p}=0.89)$.

Proteinuria was verified for $23 \%$ of donors from the ODN group but in merely $2 \%$ of donors from the LDN group. This difference was highly significant $(\mathrm{p}<0.001)$.

$\mathrm{BP}$ is represented as a mean of systolic and diastolic values. The latest $\mathrm{BP}$ reading was determined via survey, which was available during the follow-up. Mean arterial pressure averaged $102.57 \pm 8.68$ and $104.29 \pm 10.93 \mathrm{~mm}$ $\mathrm{Hg}$ in the ODN and LDN groups, repectively $(\mathrm{p}=0.396)$. Overall, $13 \%$ of all donors showed a systolic BP value 
$>140 / 80 \mathrm{~mm} \mathrm{Hg}$, which by definition is categorized as hypertensive.

In the timeframe between organ donation and followup, the proportion of donors with hypertension was $8 \%$ in the ODN group and $14 \%$ in the LDN group $(\mathrm{p}=0.52)$.

The proportion of donors with an increase in BP medication after DN amounts to 21.4 and $25.5 \%$ in the ODN and LDN group, respectively $(\mathrm{p}=0.29)$. This cohort included donors who only began taking BP medication after $\mathrm{DN}$ as well as donors who had to increase their BP medication post $\mathrm{DN}$.

Symptoms of fatigue syndrome, such as mental or physical daytime tiredness, weakness or exhaustion with diminished drive, were declared by $17 \%$ of donors from the ODN group and $8 \%$ of donors from the LDN group $(\mathrm{p}=0.152)$.

\section{Desire to Have Children after DN}

Only one female donor from the ODN group, whose data for questioning was not available, was in a childbearing age. In total, 15 female donors in the LDN group (15\% of all female donors in that group) were within the childbearing age. Two women (13\%) in this age group had each an uncomplicated pregnancy and a healthy child after live DN. One of these pregnancies was induced through in-vitro fertilization. Furthermore, 2 more women $(13 \%)$ reported an unfulfilled wish for a child, one of whom planned a pregnancy with the help of in-vitro fertilization. The remaining 11 women $(73 \%)$ had no desire for a child after kidney donation. No unwanted pregnancies occurred in this group.

\section{Discussion}

A few years ago, the consensus was that living kidney donation does not pose a long-term health risk to the donor and post-donation life expectancy was similar to that in the normal population [1]. However, more recently, large studies described an increased long-term risk of end-stage renal disease among donors [9-11].

In their recent work, Grams et al. [12] combined demographic and health characteristics to estimate the projected long-term risk of end-stage renal disease among living kidney donor candidates. This new approach may help to improve donor selection in the future.

In large transplant centers, the laparoscopic approach has overtaken the ODN due to its superiority in optimizing postoperative pain, reducing hospital stay, earlier recovery and return to the donor's daily routine, as well as an improved cosmetic result [13]. In addition, these advantages of LDN are not accompanied by inferior graft function $[14,15]$. Most donors would choose the minimally invasive method in the hypothetical scenario of a repeated donation [16].

In the present study, total operating time was significantly shorter in the LDN group. Nicholson et al. [13] reported an average operating time in the LDN group of 160 versus $150 \mathrm{~min}$ in the ODN group. Øyen et al. [17] required an average of $180 \mathrm{~min}$ for LDNs versus $140 \mathrm{~min}$ for ODNs with an average WIZ of 270 and $90 \mathrm{~s}$ for the LDN and ODN group, respectively. The shorter operating time in the LDN group is most likely a result of surgeon experience. Previously, we were able to show that total operating time and warm ischemia time for the pure laparoscopic non-hand-assisted DN significantly decreased along with surgeon experience [18].

All grade III Clavien complications included perioperative hemorrhage.

The rate of primary complications ( $\geq$ Clavien grade III) in our study is comparable with that from Mjøen et al. [19]. Patel et al. [20] reported a rate of $4.2 \%$ for major complications. In both studies, intraoperative organ injury and hemorrhage were reported as primary complications. The authors defined the following risk factors for primary complications after donation: obesity, smoking and age $>50$ years. Lucas et al. [21] compared outcomes after LDN and after hand-assisted LDN (HALDN). The complication rate was $0.7 \%$ in the LDN group and $0.9 \%$ in the HALDN group. Complications included a revision for postoperative hemorrhage (LDN) and a wound infection (HALDN) [21].

Two out of 30 patients in the ODN group required revision of an incisional hernia. No incisional hernias occurred after LDN. Dolce et al. [22] reported the same number of hernias after both ODN and LDN.

In the present study, the duration of sick leave was not different between the 2 groups. This is in line with previous results from Nicholson et al. [13], who compared postoperative morbidity and time to return to work between ODN and LDN.

Proteinuria indicates nephron hyperfiltration and may be an early indicator of renal parenchymal damage. A review by Garg et al. [23] describes independent risk factors, which may promote post-donation proteinuria, and showed that male donors were more prone to develop significant proteinuria than female donors. Furthermore, they stated that the extent of proteinuria following live donation is dependent on duration of postoperative follow-up [23]. In the present study, the incidence of proteinuria was significantly higher in the ODN group com- 
pared to the LDN group ( $n=6:$ ODN vs. $n=2: L D N, p=$ $0.001)$.

Mean arterial BP at the time of postoperative follow-up was within a physiologic range and averaged $102.57 \pm 8.68$ $\mathrm{mm} \mathrm{Hg}$ in the ODN group and 104.29 $\pm 10.93 \mathrm{~mm} \mathrm{Hg}$ in the LDN group without any significant difference between groups $(\mathrm{p}=0.396)$. The proportion of patients who developed post-donation hypertension requiring medical treatment was comparable between groups. When looking at both cohorts $13 \%$ of donors showed increased BP measurements following DN. Previous studies have investigated the long-term effects of DN on BP independent of the surgical technique used. Segev et al. [24] and Berber et al. [25] reported in their follow-up that after 6 or alternatively 5 years post donation, $7 \%$ of donors had developed hypertension [24, 25]. Berber et al. [25] concluded that in contrast to the general population the incidence of hypertension was greater in donors $>55$ years when follow-up was beyond 10 years. Naganuma et al. [26] compared the cardiovascular risk of live donors with patients, who underwent nephrectomy due to other reasons. They reported a hypertension rate of $23 \%$ of live donors and draw attention to the importance of diligent postoperative medical follow-up of the donor [26]. During their follow-up of 12 years, Ibrahim et al. [1] determined that $7 \%$ of live donors had newly diagnosed hypertension post donation. Furthermore, they found that the risk of hypertension correlates with age and the BMI value [1]. Hence, it seems that the risk factors for the development of hypertension after live kidney donation are similar to those present in the general population [1]. In the literature, the proportion of live kidney donors who had to be treated with antihypertensives post donation is described as $21-24 \%[1,27]$. In the present study, the proportion of live kidney donors who had to be started on antihypertensives or who had to increase their medications post donation was at $24.6 \%$. Thus, our results do not differ from other published data in this regard. The development of hypertension is often caused multifactorial. Our results reiterate the need for proper post-donation medical care and for a healthy lifestyle in order to minimize long-term morbidity.

Only a few studies on post-donation pregnancy rates exist $[5,6]$. Reisaeter et al. [5] claimed a potentially higher risk for preeclampsia in pregnant women, who previously donated a kidney. In our study, $72 \%$ of donors in the LDN group and $67 \%$ of donors in the ODN group were women. Of these, 15 were in the child-bearing age range of 18-45 years at the time of donation.

In total, 2 women each bore a healthy child without complications during pregnancy with one having preg- nancy induced via in-vitro fertilization. Additionally, 2 women reported an unfulfilled desire to have children, one of whom was planning pregnancy via in-vitro fertilization. The remaining female donors had fulfilled their desire to have children. Some of the female donors donated a kidney to their own child, which was affected by renal disease, so that the decision not to have another child very likely precipitated out of these circumstances. These results show that postoperative child wish as well as pregnancy incidence among female kidney donors in the child-bearing age is rather low. Despite these preliminary retrospective data, female donors willing to become pregnant should be informed about the increased risk of post-donation preeclampsia.

Questions surrounding fatigue as a long-term effect of live kidney donation was investigated by Kok et al. [28]. The researchers compared the open surgical technique (mini-incision DN) with the LDN and questioned their donors with the help of the Multidimensional Fatigue Inventory-20 (MFI-20). In particular, generalized and physical fatigue was significantly increased post donation compared to pre-donation. No difference was observed when comparing the effect of the surgical technique (mini-incision versus LDN on fatigue incidence [28]. de Groot et al. [29] showed a significant impact of post-donation fatigue on the donor's quality of life. For our study purposes, we extracted questions from the MFI-20 covering most of the important parameters such as physical or mental weariness, exhaustion and debility. While $17 \%$ of donors in the ODN and $8 \%$ of donors in the LDN group declared being fatigued, no significant difference was found between the 2 groups. Whether live organ donation promotes the development of fatigue syndrome could not be answered with the current data. Larger prospective studies are necessary to determine a possible link between the 2 .

We asked donors about their willingness to donate again in the hypothetical scenario of repeat donation. Overall $96 \%$ of donors would undergo live donor nephrectomy again. For the next question, donors had to choose which surgical technique (ODN vs. LDN) they would prefer in case of repeated surgery. Hereby, $99 \%$ in the LDN group stated that they would choose the same laparoscopic approach, while only $67 \%$ of donors in the ODN group, knowing about the alternative minimally invasive option, said they would repeat the open surgical technique again. This preference for the laparoscopic technique was highly significant and supports previous results by Giessing et al. [16]. In their study, $85 \%$ of donors who underwent LDN stated they would choose this 
approach again [16]. These data underscore the high acceptance of minimally invasive techniques for live DN. This could increase the willingness to donate among potential live kidney donors.

\section{Conclusions}

Based on our results, we conclude that from the donor's perspective, LDN is more favorable than the open approach, given its reduced peri- and postoperative mor- bidity. The preference to undergo LDN instead of ODN in a hypothetic scenario of repeat donation indicates a broad acceptance of minimally invasive surgery among donors. To what extent live kidney donation impacts the quality of life of young donors, especially of women of child-bearing age, warrants further investigation.

\section{Disclosure Statement}

All authors declare that they have no competing interests.

\section{References}

1 Ibrahim HN, Foley R, Tan L, et al: Long-term consequences of kidney donation. $\mathrm{N}$ Engl J Med 2009;360:459-469.

2 Kok NF, Lind MY, Hansson BM, et al: [Donor nephrectomy: less fatigue and better quality of life following laparoscopic kidney removal compared with an open procedure by miniincision: blind randomised study]. Ned Tijdschr Geneeskd 2007;151:1352-1360.

3 Kayler LK, Meier-Kriesche HU, Punch JD, et al: Gender imbalance in living donor renal transplantation. Transplantation 2002;73: 248-252.

4 Davison JM, Dunlop W: Renal hemodynamics and tubular function normal human pregnancy. Kidney Int 1980;18:152-161.

5 Reisaeter AV, Røislien J, Henriksen T, Irgens LM, Hartmann A: Pregnancy and birth after kidney donation: the Norwegian experience. Am J Transplant 2009;9:820-824.

6 Ibrahim HN, Akkina SK, Leister E, et al: Pregnancy outcomes after kidney donation. Am J Transplant 2009;9:825-834.

7 Lentine KL, Patel A: Risks and outcomes of living donation. Adv Chronic Kidney Dis 2012;19:220-228.

8 Schostak M, Wloch H, Müller M, Schrader M, Offermann G, Miller K: Optimizing open live-donor nephrectomy - long-term donor outcome. Clin Transplant 2004;18:301-305.

-9 Steiner RW, Ix JH, Rifkin DE, Gert B: Estimating risks of de novo kidney diseases after living kidney donation. Am J Transplant 2014; 14:538-544.

$\checkmark 10$ Muzaale AD, Massie AB, Wang MC, et al: Risk of end-stage renal disease following live kidney donation. JAMA 2014;311:579-586.

11 Mjøen G, Hallan S, Hartmann A, et al: Longterm risks for kidney donors. Kidney Int 2014; 86:162-167.

12 Grams ME, Sang Y, Levey AS, et al: Kidneyfailure risk projection for the living kidney- donor candidate. N Engl J Med 2016;374: 411-421.

13 Nicholson ML, Kaushik M, Lewis GR, et al: Randomized clinical trial of laparoscopic versus open donor nephrectomy. Br J Surg 2010; 97:21-28.

14 Nanidis TG, Antcliffe D, Kokkinos C, et al: Laparoscopic versus open live donor nephrectomy in renal transplantation: a metaanalysis. Ann Surg 2008;247:58-70.

15 Ruiz-Deya G, Cheng S, Palmer E, Thomas R, Slakey D: Open donor, laparoscopic donor and hand assisted laparoscopic donor nephrectomy: a comparison of outcomes. J Urol 2001;166:1270-1273; discussion 12731274.

16 Giessing M, Reuter S, Deger S, et al: Laparoscopic versus open donor nephrectomy in Germany: impact on donor health-related quality of life and willingness to donate. Transplant Proc 2005;37:2011-2015.

17 Øyen O, Andersen M, Mathisen L, et al: Laparoscopic versus open living-donor nephrectomy: experiences from a prospective, randomized, single-center study focusing on donor safety. Transplantation 2005;79:12361240.

18 Friedersdorff F, Werthemann P, Cash H, et al: Outcomes after laparoscopic living donor nephrectomy: comparison of two laparoscopic surgeons with different levels of expertise. BJU Int 2013;111:95-100.

19 Mjøen G, Øyen O, Holdaas H, Midtvedt K, Line PD: Morbidity and mortality in 1022 consecutive living donor nephrectomies: benefits of a living donor registry. Transplantation 2009;88:1273-1279.

20 Patel S, Cassuto J, Orloff M, et al: Minimizing morbidity of organ donation: analysis of factors for perioperative complications after living-donor nephrectomy in the United States. Transplantation 2008;85:561-565.
21 Lucas SM, Liaw A, Mhapsekar R, et al: Comparison of donor, and early and late recipient outcomes following hand assisted and laparoscopic donor nephrectomy. J Urol 2013;189: 618-622.

22 Dolce CJ, Keller JE, Walters KC, et al: Laparoscopic versus open live donor nephrectomy: outcomes analysis of 266 consecutive patients. Surg Endosc 2009;23:1564-1568.

23 Garg AX, Muirhead N, Knoll G, et al; Donor Nephrectomy Outcomes Research (DONOR) Network: Proteinuria and reduced kidney function in living kidney donors: a systematic review, meta-analysis, and meta-regression. Kidney Int 2006;70:1801-1810.

24 Segev DL, Muzaale AD, Caffo BS, et al: Perioperative mortality and long-term survival following live kidney donation. JAMA 2010; 303:959-966.

25 Berber I, Tellioglu G, Kilicoglu G, et al: Medical risk analysis of renal transplant donors. Transplant Proc 2008;40:117-119.

26 Naganuma T, Takemoto Y, Taiyou O, et al: Risk of cardiovascular disease in kidney donors as a chronic kidney disease cohort. Mol Med Rep 2012;5:7-11.

27 Kim SH, Hwang HS, Yoon HE, et al: Longterm risk of hypertension and chronic kidney disease in living kidney donors. Transplant Proc 2012;44:632-634.

28 Kok NF, Lind MY, Hansson BM, et al: Comparison of laparoscopic and mini incision open donor nephrectomy: single blind, randomised controlled clinical trial. BMJ 2006; 333:221.

29 de Groot IB, Stiggelbout AM, van der Boog PJ, Baranski AG, Marang-van de Mheen PJ; PARTNER-Study Group: Reduced quality of life in living kidney donors: association with fatigue, societal participation and predonation variables. Transpl Int 2012;25: 967-975. 